Pesq. Vet. Bras. 29(12):963-968, dezembro 2009

\title{
Ultimobranchial gland of freshwater catfish, Heteropneustes fossilis, in response to calcitonin administration ${ }^{1}$
}

\author{
Ajai K. Srivastav² ${ }^{*}$, Sarita Singh², Diwakar Mishra ${ }^{2}$ and S.K. Srivastav²
}

\begin{abstract}
Srivastav A.K., Singh S., Mishra D. \& Srivastav S.K. 2009. Ultimobranchial gland of freshwater catfish, Heteropneustes fossilis, in response to calcitonin administration. Pesquisa Veterinária Brasileira 29(12):963-968. Department of Zoology, DDU Gorakhpur University, Gorakhpur 273 009, India. E-mail: ajaiksrivastav@hotmail.com

The absence o!!f a hypocalcemic effect of calcitonin (CT) in fishes has been suggested due to exceedingly high plasma levels of CT; the fish may be saturated with respect of circulating CT and therefore unable to respond to exogenously administered CT. Earlier it has been suggested that a hypocalcemic action of injected CT may be obscured by changes in the release of endogenous $\mathrm{CT}$ and other calcium regulating hormones. In this study we have used artificial freshwater, calcium-deficient freshwater and calcium-rich freshwater and injected the fish with CT. The aim behind selecting these media were (i) in calcium-deficient medium there would be reduced circulating levels of CT, (ii) in calciumrich medium there would be diminished secretion of prolactin (this hormone is hypercalcemic in fish), and (iii) by keeping the fish in calcium-rich medium we can test the antihypercalcemic action of CT. Moreover, the present study would reveal the changes in the ultimobranchial gland (UBG) after keeping the fish in all the above three media and/or injecting the fish with CT. Freshwater catfish, Heteropneustes fossilis, were administered intraperitoneally daily with vehicle or $0.5 \mathrm{U} / 100 \mathrm{~g}$ body wt of salmon calcitonin (CT) and kept in artificial freshwater, calcium-rich freshwater and calcium-deficient freshwater for 10 days. Blood samples were collected on 1, 3, 5, and 10 days following the treatment and analyzed for serum calcium levels. The ultimobranchial gland (UBG) was also fixed for histological studies on these intervals. In artificial freshwater there was no change in the serum calcium levels of calcitonin-injected fish. The ultimobranchial gland of calcitonin-injected fish exhibited a progressive decrease in the nuclear volume from day 5 onwards. On day 10 vacuolization in the gland was also noticed. In vehicle-injected fish (control) kept in calcium-rich freshwater hypercalcemia has been noticed which persists till the end of the experiment. In calcitonin-treated fish maintained in calcium-rich freshwater there is no change in serum calcium level as compared to vehicle-injected fish. In vehicleinjected fish the UBG depicts decreased staining response and increased nuclear volume at day 5 . On day 10 the nuclear volume is further increased and few degenerating cells have been noticed. Calcitonin fails to induce any histological change in the UBG as compared to control. In vehicle-injected fish kept in calcium-deficient freshwater the serum calcium levels decrease from day 1 to day 3 . The levels exhibit hypercalcemia on day 10. CT treatment to the fish kept in calcium-deficient freshwater evokes a decrease in the calcium levels on day 1 and day 3 . A significant hypercalcemia has been noticed on day 5 and day 10. In vehicle-injected fish kept in calcium-deficient freshwater the UBG reveals a decreased staining response on day 10 . In CT-injected fish maintained in calcium-deficient freshwater the UBG depicts an increased nuclear volume and few exhausted cells on day 10. It can be concluded that CT can provoke hypocalcemia only when the fish is kept in medium
\end{abstract}

${ }^{1}$ Received on November 24, 2008.

Accepted for publication on September 11, 2009.
2 Department of Zoology, DDU Gorakhpur University, Gorakhpur 273 009, India. *Corresponding author: ajaiksrivastav@hotmail.com 
which reduces the circulating levels of this hormone. The UBG of the fish kept in different calcemic media responded in a manner to indicate that it produces hypocalcemic factor - CT.

INDEX TERMS: Calcitonin, ultimobranchial gland, calcium, fish, Heteropneustes fossilis.

\section{INTRODUCTION}

In mammals the hypocalcemic hormone, calcitonin is secreted from the calcitonin $(C)$ cells which are derived from the neural crest and during embryonic development these cells migrate and incorporated into the thyroid and parathyroid IV (Dacke 1979, Srivastav \& Rani 1988, Miller 2006). However, these cells remain separate from the thyroid gland in non-mammals and form a discrete organ the ultimobranchial gland (UBG). In fishes administration of calcitonin (CT) produced conflicting results - no effect, hypocalcemia and hypercalcemia (Wendelaar Bonga \& Pang 1991, Chakrabarti \& Mukherjee 1993, Oughterson et al. 1995, Srivastav et al. 1998a,b, Mukherjee et al. 2004). This conflict regarding the effect of CT in fishes has led some workers to suggest that CT is involved either with osmotic regulation (Yamauchi et al. 1978), sex-related phenomenon (Yamane \& Yamada 1977, Suzuki 2005), skeletal protection during periods of high calcium demands (Wendelaar Bonga \& Pang 1991) and to protect scales from excess degradation of calcium at vitellogenesis (Suzuki et al. 2000). CT has also been suggested to control dietary calcium uptake (Suzuki et al. 1999) and inhibit calcium transport in fish gills (Wagner et al. 1997, Mukherjee et al. 2004). As yet no definite functions of CT (Hirsch et al. 2001, Clark et al. 2002, Miller 2006, Nag et al. 2007) have been established and more work is necessary to establish its functions in fishes.

The absence of a hypocalcemic effect of calcitonin (CT) in fishes has been suggested due to exceedingly high plasma levels of CT; the fish may be saturated with respect of circulating CT and therefore unable to respond to exogenously administered CT. Wendelaar Bonga (1980) has suggested that a hypocalcemic action of injected CT may be obscured by changes in the release of endogenous CT and other calcium regulating hormones. In this study we have used artificial freshwater, calcium-deficient freshwater and calcium-rich freshwater and injected the fish with CT. The aim behind selecting these media were (i) in calciumdeficient medium there would be reduced circulating levels of CT, (ii) in calcium-rich medium there would be diminished secretion of prolactin (this hormone is hypercalcemic in fish), and (iii) by keeping the fish in calcium-rich medium we can test the antihypercalcemic action of CT. Moreover, the present study would reveal the changes in the ultimobranchial gland (UBG) after keeping the fish in all the above three media and/or injecting the fish with CT. To the best of our knowledge, there exists no study regarding the effects of CT on the UBG of fish kept in calcium-deficient or calciumrich media.

In this study we report the effect of calcitonin on the ultimobranchial gland of the freshwater catfish, Heterop- neustes fossilis which were kept in different calcium environments. H. fossilis was selected because it is hardy, readily available, easy to handle and can be kept alive for longer duration in the aquaria. This is a common food fish and forms an important species in many water resources mainly ponds, ditches, swamps, marshes and sometimes occurs in muddy rivers (Rainboth 1996). This species is found in India, Pakistan, Sri Lanka, Nepal, Bangladesh, Burma, Thailand and Vietnam (Berra 2007).

\section{MATERIALS AND METHODS}

The freshwater catfish, Heteropneustes fossilis (body wt. $50 \pm 9 \mathrm{~g}$ and size $16 \pm 3.5 \mathrm{~cm}$ ) were collected locally from Ramgarh Lake, acclimatized under laboratory conditions in dechlorinated tap water for two weeks. After acclimation they were divided into six groups each containing 48 fish and subjected to the following treatments:

Group A. Fish were maintained in artificial freshwater and were daily injected intraperitoneally (i.p.) with vehicle $(0.1 \mathrm{ml}$ of $0.6 \% \mathrm{NaCl} / 100 \mathrm{~g}$ body wt).

Group B. Fish were kept in artificial freshwater and were daily injected i.p. with $0.5 \mathrm{U} / 100 \mathrm{~g}$ body wt of salmon calcitonin.

Group C. Fish were kept in calcium-rich freshwater and were injected daily i.p. with vehicle $(0.1 \mathrm{ml}$ of $0.6 \% \mathrm{NaCl} / 100 \mathrm{~g}$ body wt).

Group D. Fish were kept in calcium-rich freshwater and injected i.p. daily with $0.5 \mathrm{U} / 100 \mathrm{~g}$ body wt of salmon calcitonin.

Group E. Fish were kept in calcium-deficient freshwater and were daily injected i.p. with vehicle $(0.1 \mathrm{ml}$ of $0.6 \% \mathrm{NaCl} / 100 \mathrm{~g}$ body wt).

Group F. Fish were kept in calcium-deficient freshwater and were daily injected i.p. with $0.5 \mathrm{U} / 100 \mathrm{~g}$ body wt of salmon calcitonin.

Calcitonin used in groups B, D and $\mathrm{F}$ was dissolved in $0.6 \%$ $\mathrm{NaCl}$ solution. The fish were not fed $24 \mathrm{~h}$ before and during the experiment.

Different artificial media were prepared as follows:

(a) Artificial freshwater. Distilled water containing $2.10 \mathrm{mM} \mathrm{NaCl}$, $0.45 \mathrm{mM} \mathrm{Na}_{2} \mathrm{SO}_{4}, 0.06 \mathrm{mM} \mathrm{KCl}, 0.8 \mathrm{mM} \mathrm{CaCl}_{2}, 0.20 \mathrm{mM} \mathrm{MgCl}_{2}$. pH of the solution was adjusted to 7.6 with $\mathrm{NaHCO}_{3}$

(b) Calcium-rich freshwater. $13.4 \mathrm{mM} \mathrm{CaCl}_{2}$ was added to the artificial freshwater.

(c) Calcium-deficient freshwater. same as artificial freshwater without $\mathrm{CaCl}_{2}$.

Twelve fishes from each group were anesthetized with MS 222 and blood samples were taken by sectioning of the caudal peduncle $2 \mathrm{~h}$ after the last injection on 1, 3, 5 and 10 days of the treatment. The sera were separated and analyzed for calcium according to the method of Trinder (1960). After collection of blood samples, the area adjoining the heart along with the esophagus (as UBG has been found in this region) were removed and fixed in aqueous Bouin's fluid. Tissues thus fixed were routinely processed in graded series of alcohols, cleared in xylene and embedded in paraffin. Serial 
sections were cut at $6 \mu \mathrm{m}$ and stained with hematoxylin-eosin (HE).

Nuclear indexes (maximal length and maximal width) were determined (50 nuclei were measured per specimen, thus 300 nuclei were measured from six specimens) with the aid of ocular micrometer and then the nuclear volume was calculated as:

Volume $=4 / 3 p a b^{2}$

Where ' $a$ ' is the major semiaxis and ' $b$ ' is the minor semiaxis.

Data are reported as mean \pm S.E. for six specimens (although 12 specimens were taken for each group but data from 6 specimens were taken into account) and Student's t test was used to determine statistical significance. Each experimental group was compared to its specific time control group.

\section{RESULTS}

\section{(i) Artificial freshwater (groups A and B)}

The serum calcium levels of calcitonin-treated fish (group B) depicted no significant change as compared to those of vehicle-injected specimens (group A) (Fig.1).

In vehicle-injected fish (group A) the UBG usually possessed a solid parenchyma which contained cell cords
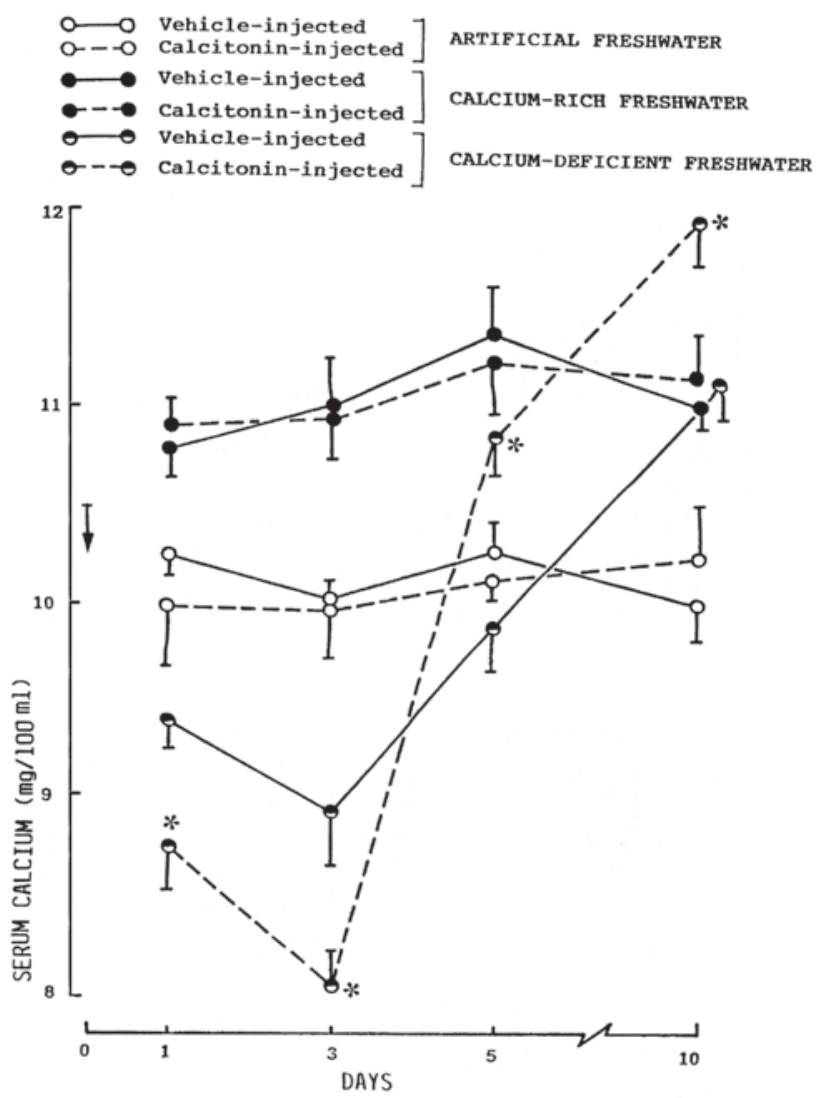

Fig.1. Changes in the serum calcium levels of vehicle (control) or calcitonin-treated (experimental) fish maintained either in artificial freshwater, calcium-rich freshwater or calcium-deficient freshwater. Each value represents mean \pm S.E. of six specimens. Asterisk indicates significant differences from vehicle-injected group $(\mathrm{P}<0.05)$. Data of calcitonin-treated (experimental) fish were compared with vehicle-injected (control) fish in each medium. Only data which are significant are marked with an asterisk.

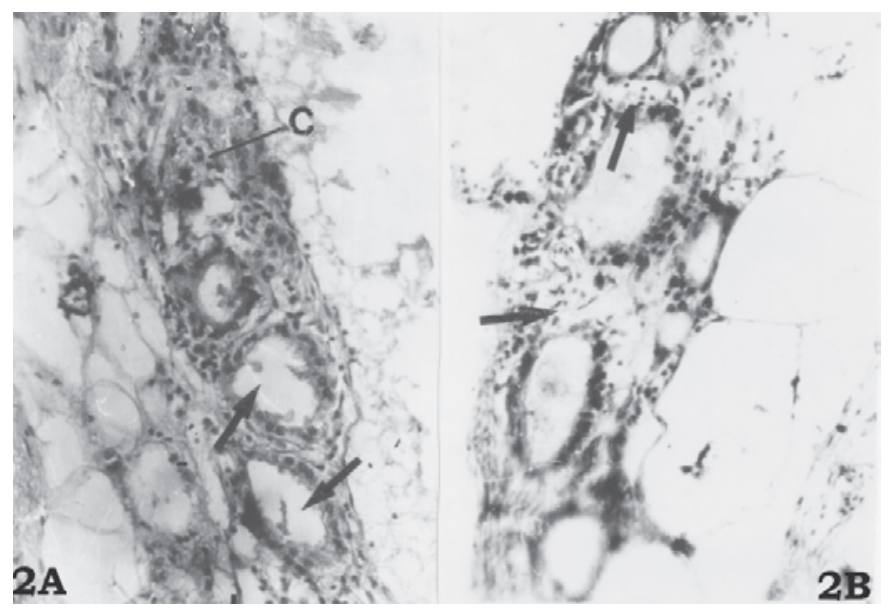

Fig.2. (A) Ultimobranchial gland of 5 days vehicle-injected (control) fish maintained in artificial freshwater. Note the presence of follicles (arrows) and cords (C). HE, 200x. (B) Ultimobranchial gland of 10 days calcitonin-treated fish kept in artificial freshwater showing vacuolization (arrows). HE, 200x.
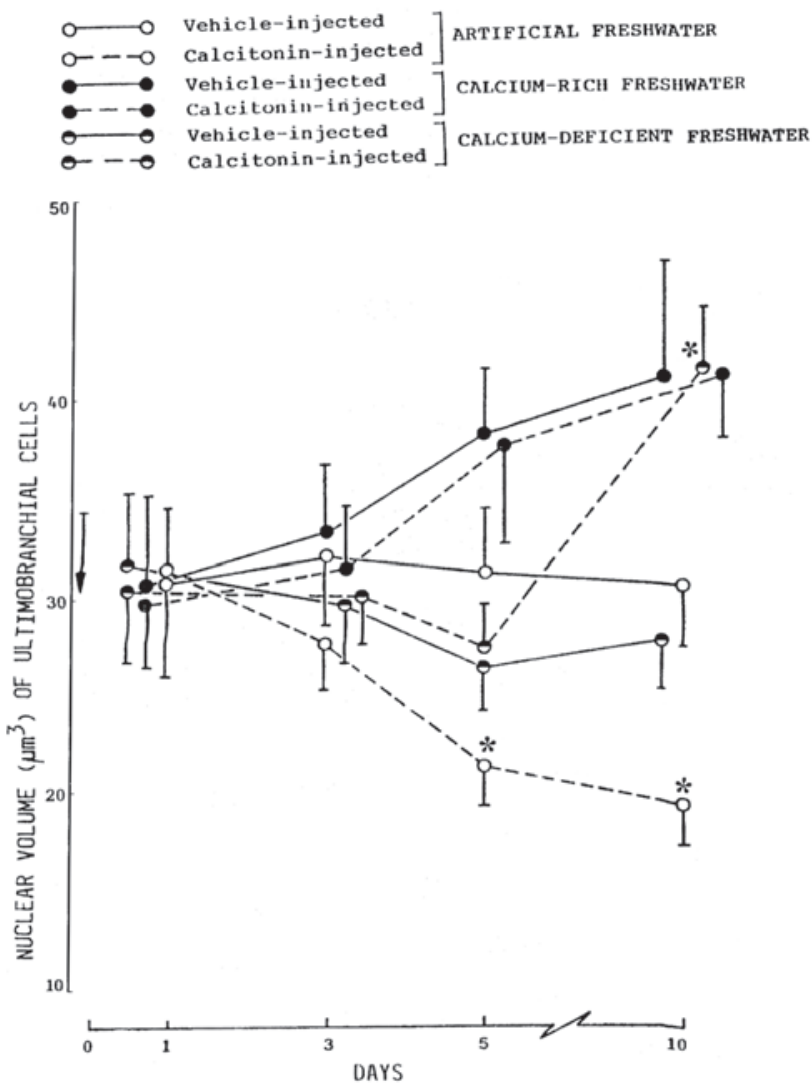

Fig.3. Nuclear volume of ultimobranchial cells of vehicle (control) or calcitonin-treated (experimental) fish maintained either in artificial freshwater, calcium-rich freshwater or calciumdeficient freshwater. Each value represents mean \pm S.E. of six specimens. Asterisk indicates significant differences from vehicle-injected group $(P<0.05)$. Data of calcitonin-treated (experimental) fish were compared with vehicle-injected (control) fish in each medium. Only data which are significant are marked with an asterisk. 
and small follicles (Fig.2 A). All the cells were alike. Their cell boundaries were indistinct. When stained with $\mathrm{HE}$, the cytoplasm of these cells was noticed slightly eosinophilic. The nuclei were generally rounded, oval or vesicular in shape.

Uptil day 3 following the CT treatment (group B) there was no significant histological change in the UBG. From day 5 onwards there was a progressive decrease in the nuclear volume of UBG cells (Fig.3) and degenerative changes (vacuolization of cytoplasm) were seen on day 10 (Fig.2B).

\section{(ii) Calcium-rich freshwater (groups C and D)}

Serum calcium level in the specimens of group $\mathrm{C}$ (vehicle-injected) showed a progressive increase up to day 5 . On day 10 , a slight decrease in the serum calcium level was recorded though it still remained hypercalcemic (Fig.1).

CT treatment (group D) was ineffective regarding serum calcium level which was more or less similar to that of group C (Fig.1).

Up to day 3 following vehicle-injection (group C), there was no change in the histological details of UBG. The UBG depicted a decrease in the staining response (Fig.4A) and an increase in nuclear volume on day 5 (Fig.3). On day 10 , the gland became compact, the nuclear volume increases (Fig.3) and a few degenerating cells were discerned (Fig.4B).

CT failed to induce any histological change in group $D$ as the histological structure of UBG was similar to the gland of vehicle-injected specimens.

\section{(iii) Calcium-deficient freshwater (groups E and F)}

A slight decrease in the serum calcium level of vehicleinjected fish (group E) was recorded on day 1 (Fig.1). This

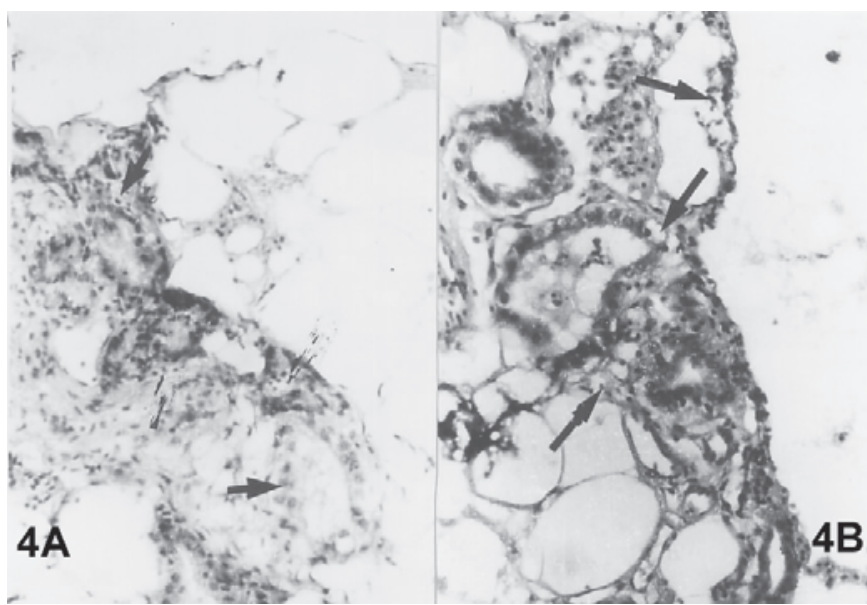

Fig.4. (A) Ultimobranchial gland of 5 days vehicle-injected (control) fish kept in calcium-rich freshwater showing decreased staining response (arrow). HE, 200x. (B) Ultimobranchial gland of 10 days vehicle-injected (control) fish kept in calcium-rich freshwater. Note certain degenerating cells (arrows). HE, 200x.

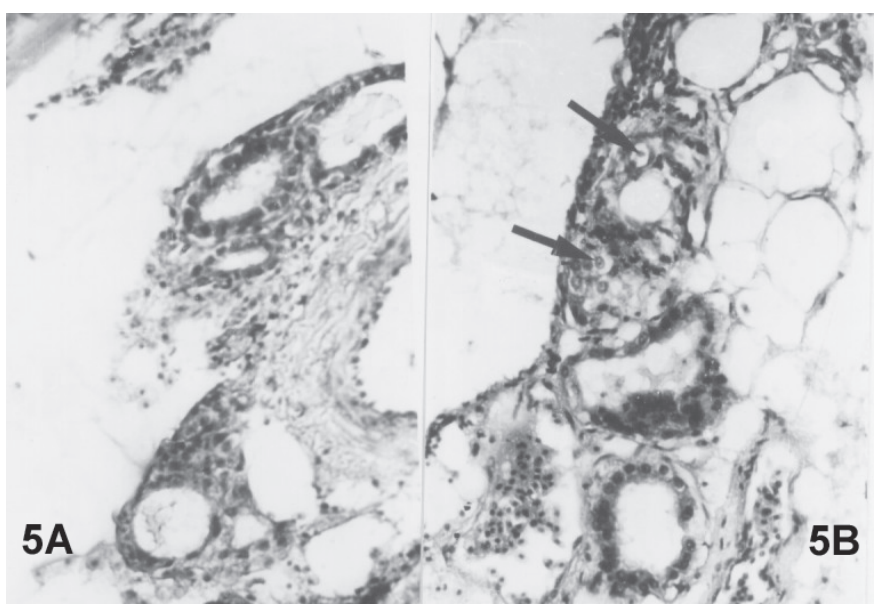

Fig.5. (A) Decreased staining response of the ultimobranchial gland of 10 days vehicle-injected (control) fish kept in calcium-deficient freshwater. HE, 200x. (B) Ultimobranchial gland of 10 days calcitonin-injected fish kept in calciumdeficient freshwater exhibiting few exhausted cells (arrows). HE, 200x.

response continued on day 3 (Fig.1). From day 5 the levels showed a trend to increase which resulted into hypercalcemia on day 10 (Fig.1).

CT treatment (Group F) evoked a decrease in the serum calcium level on day 1 which persisted till day 3. Thereafter, the value exhibited a significant hypercalcemia on day 5 . This response increased progressively till day 10 (Fig.1).

No change was noticed in the UBG of vehicle-injected fish (group E) uptil day 5. However, there was a decrease in the staining response of the UBG cells on day 10 (Fig.5A). The nuclear volume of these cells displayed no significant change (Fig.3).

In CT treated fish (group F) the UBG cells remained unaffected till day 5. However, on day 10 increased nuclear volume (Fig.3) and few exhausted cells (Fig.5B) were noticed.

\section{DISCUSSION AND CONCLUSION}

In the present study, the administration of CT to Heteropneustes fossilis maintained in artificial freshwater causes inactivity in the UBG which is evident by decreased nuclear volume of UBG cells. This is in accord with similar findings reported by Peignoux-Deville et al. (1975), Wendelaar Bonga (1980) and Srivastav et al. (1989) as these investigators have also noticed inactivity in the gland after CT administration. The vacuolization observed in CT administered $H$. fossilis can be associated with the continuous disuse of the UBG cells in response to CT administration.

In the present study the fish subjected to calciumdeficient freshwater and/or CT treatment exhibit an increased activity of UBG on day 10 . This may be due to the observed elevation of serum calcium level at this duration. No difference has been noticed in the changes in UBG of $H$. fossilis whether they are treated with either 
calcium chloride or calcium chloride and CT. In both these treatments, the UBG exhibits hyperactivity which can be attributed to the increased calcium levels. To the best of our knowledge, there exists no study regarding the effects of CT on the UBG of fish kept in calcium-deficient or calcium-rich media. Hence, in this regard the findings of the present study are new and could not be compared with the observations of other investigators. Enhanced activity/secretion of CT from the fish UBG has been reported in the past by several investigators in response to experimentally induced hypercalcemia (Lopez et al. 1968, Lopez \& Bagot 1971, Chan 1972, Lopez 1973, Peignoux-Deville et al. 1975, Swarup \& Srivastav 1984, Fouchereau-Peron et al. 1986, Suzuki et al. 1999, Kaida \& Sasayama 2003). Hyperactivity of ultimobranchial gland after induced hypercalcemia has also been reported from non-piscine vertebrates (Ziegler et al. 1970, Dubewar et al. 1978, Suzuki et al. 1982, 1984, Srivastav \& Rani 1991, 1992, Srivastav et al. 1994, 2008, Srivastav \& Yadav 2008, Yadav \& Srivastav 2008).

It is concluded from this study that (i) CT provokes hypocalcemia in fish only when they are kept in a medium which can reduce the circulating levels of CT, (ii) the UBG of normal fish respond to CT administration by depicting inactivity, and (iii) UBG gets activated when the fish is kept in calcium-rich medium and this activity of UBG is not influenced by administration of CT.

\section{REFERENCES}

Berra T. M. 2007. Freshwater fish distribution. University of Chicago Press, p.615.

Chakrabarti P. \& Mukherjee D. 1993. Studies on the hypocalcemic actions of salmon calcitonin and ultimobranchial gland extracts in the freshwater teleost Cyprinus carpio. Gen. Comp. Endocrinol. 90:267273.

Chan D.K.O. 1972. Hormonal regulation of calcium balance in teleost fish. Gen. Comp. Endocrinol. 3:411-420.

Clark M.S., Bendell L., Power D.M., Warner S., Elgar G. \& Ingleton P.M. 2002. Calcitonin: Characterization and expression in a teleost fish, Fugu rubripes. J. Molecular Endocrinol. 28:111-123.

Dacke C.G. 1979. Calcium Regulation in Submammalian Vertebrates. Academic Press, New York, p.222.

Dubewar D.M., Suryawanshi S.A. \& Rege U.G. 1978. Effect of experimental hypercalcemia on the ultimobranchial gland of lizard with special reference to age. Z. Mikrosk. Anat. Forsch. 92:547-552.

Fouchereau-Peron M., Arlot-Bonnemains Y., Moukhtar M.S. \& Milhaud G. 1986. Adaptation of rainbow trout (Salmo gairdneri) to sea water: Changes in calcitonin levels. Comp. Biochem. Physiol. 83A:83-87.

Hirsch P.F., Lester G.E. \& Talmage R.V. 2001. Calcitonin, an enigmatic hormone: does it have a function? J. Musculoskel. Neuron Interact 1:299-305.

Kaida N. \& Sasayama Y. 2003. Dynamics of plasma Ca and calcitonin levels in stonefish (Inimicus japonicus) administered ahigh-Ca solution into the stomach. Zool. Sci. 20:353-356.

Lopez E. 1973. Etude morphologique to physiologique de l'es cellulaire des poissons teleosteens. Mem. Mus. Nat. Hist. 80A:190.

Lopez E. \& Bagot E. 1971. L'es cellulaire d'un poisson teleosteen Anguilla anguilla L. III. Etude histologique et histophysiologique eu oours de la maturation provoquee per injections d'extrait hypophysaire de carpe. Z. Zellforsch. 117:176-190.
Lopez E., Peignoux-Deville J. \& Bagot E. 1968. Etude histophysiologique du carps ultimobranchial dun teleosteen, Anguilla anguilla L. au cours d'hypercalcemia experimentales. C.R. Acad. Sci. Paris 267D:15311534.

Miller S. 2006. Calcitonin- guardian of the mammalian skeleton or is it just a fish story? Endocrinology 147:4007-4009.

Mukherjee D., Sen U., Bhattacharya S.P. \& Mukherjee D. 2004. The effects of calcitonin on plasma calcium levels and bone metabolism in the fresh water teleost Channa punctatus. Comp. Biochem. Physiol. A Mol. Integr. Physiol. 138:417-426.

Nag K., Kato A., Sultana N., Ogoshi M., Takei Y. \& Hirose S. 2007. Fish calcitonin receptor has novel features. Gen. Comp. Endocrinol. 154:4858 .

Oughterson S.M., Munoz-Chapuli R., De Andres V., Lawson R., Heath S. \& Davies D.H. 1995. The effect of calcitonin on serum calcium levels in immature brown trout, Salmo trutta. Gen. Comp. Endocrinol. 97:42-48.

Peignoux-Deville J., Lopez E., Lallier F., Bagot E.M. \& Milet C. 1975. Responses of the ultimobranchial body in eels (Anguilla anguilla L.) maintained in sea water and experimentally matured to injections of synthetic salmon calcitonin. Cell Tissue Res. 164:73-83.

Rainboth W. J. 1996. Fishes of the Cambodian Mekong. FAO Species Identification Field Guide for Fishery Purposes. FAO, Rome, p.265.

Srivastav Ajai K. \& Rani L. 1988. Mammalian calcitonin cells: Retrospect and prospect. Biol. Struct. Morphogen. 1:17-123.

Srivastav Ajai K. \& Rani L. 1991. Response of ultimobranchial body, parathyroid gland, serum calcium and serum phosphate in the frog, Rana tigrina after prolactin administration. Europ. Arch. Biol. 102:159163.

Srivastav Ajai K. \& Rani L. 1992. Ultimobranchial body and parathyroid glands of the freshwater snake, Natrix piscator in response to vitamin D3 administration. J. Exp. Zool. 62:255-262.

Srivastav Ajai K., Rani L. \& Sasayama Y. 1994. Influence of prolactin administration on the ultimobranchial body and parathyroid glands of the freshwater snake, Natrix piscator. Okajimas Folia Anat. Japonica 71:59-66.

Srivastav Ajai K. \& Yadav Seema 2008. Prolactin effects on ultimobranchial and parathyroid glands of pigeon. North-Western J. Zoology 4:300-310.

Srivastav Ajai K., Yadav Seema, Srivastav S.K. \& Suzuki Nobuo 2008. The ultimobranchial gland in poikilotherms: Morphological and functional aspects, p.269-296. In: Haldar C., Singaravel M., PandiPerumal S.R. \& Cardinali D.P. (Eds), Experimental Endocrinology and Reproductive Biology. Science Publishers, Enfield, NH, USA.

Srivastav Ajai K., Tiwari P.R., Srivastav S.K., Sasayama Y. \& Suzuki N. 1998a. Serum calcium and phosphate levels of calcitonin treated freshwater mud eel, Amphipnous cuchia kept in different calcium environments. Netherlands J. Zool. 48:189-198.

Srivastav Ajai K., Srivastav S.K., Sasayama Y. \& Suzuki, N., 1998b. Salmon calcitonin induced hypocalcemia and hyperphosphatemia in an elasmobranch, Dasyatis akajei. Gen. Comp. Endocrinol. 109:812.

Srivastav S.P., Swarup K., Singh S. \& Srivastav Ajai K. 1989. Effects of calcitonin administration on ultimobranchial gland, Stannius corpuscles and prolactin cells in male catfish, Clarias batrachus. Arch. Biol. 100:385-392.

Suzuki K., Yoshizawa H., Yoshihara M., Sasayama Y. \& Oguro C.1982. Ultrastructural studies on the ultimobranchial glands in some lower tetrapods. Comp. Endocrinology of Calcium Regulation, Japan Sci. Soc. Press Tokyo, p.115-119.

Suzuki K., Yoshizawa H., Yoshihara M., Sasayama Y. \& Oguro C. 1984. Ultrastructure of snake ultimobranchial glands, p.203-205. In: Cohn D.V., Potts Jr J.T. \& T. Fujita T. (Eds), Endocrine Control of Bone and Calcium Metabolism. Elsevier Science Publishers B.V. 
Suzuki N. 2005. Physiological significance of calcitonin in fish. Clin. Calcium 15:139-146.

Suzuki N., Suzuki D., Sasayama Y., Srivastav Ajai K., Kambegawa A. \& Asahina K. 1999. Plasma calcium and calcitonin levels in the eels fed a high calcium solution or transferred to seawater. Gen. Comp. Endocrinol. 114:324-329.

Suzuki N., Suzuki T. \& Kurokawa T. 2000. Suppression of osteoclastic activities by calcitonin in the scales of goldfish (freshwater teleost) and nibbler fish (seawater teleost). Peptides 21:115-124.

Swarup K. \& Srivastav S.P. 1984. Structure and behaviour of ultimobranchial gland in response to vitamin $D_{3}$ induced hypercalcemia in male Clarias batrachus. Arch. Anat. Microsc. Exp. 73:223229.

Trinder P. 1960. Colorimetric microdetermination of calcium in serum. Analyst 85:889-894.

Wagner G.F., Jaworski E.M. \& Radman D.P. 1997. Salmon calcitonin inhibits whole body $\mathrm{Ca}^{2+}$ uptake in young rainbow trout. J. Endocrinol. 155:459-465.

Wendelaar Bonga S.E. 1980. Effect of synthetic salmon calcitonin and low ambient calcium on plasma calcium, ultimobranchial cells, Stannius bodies and prolactin cells in the teleost, Gasterosteus aculeatus. Gen. Comp. Endocrinol. 40:99-108.

Wendelaar Bonga S.E. \& Pang P.K.T. 1991. Control of calcium regulating hormones in the vertebrates: parathyroid hormone, calcitonin, prolactin and stanniocalcin. Int. Rev. Cytol. 128:139-213.

Yadav Seema \& Srivastav Ajai K. 2008. Ultimobranchial and parathyroid glands of the pigeon Columba livia in response to $1,25 \mathrm{OH}_{2} \mathrm{D}_{3}$ administration. Microsc. Res. Tech. 71:831-837.

Yamane S. \& Yamada J. 1977. Histological changes of the ultimobranchial gland through the life history of the masu salmon. Bull. Jap. Soc. Sci. Fish. 43:375-386.

Yamauchi H., Matsuo M., Yoshida A. \& Orimo H. 1978. Effect of eel calcitonin on serum electrolytes in the eel, Anguilla japonica. Gen. Comp. Endocrinol. 34:343-346.

Ziegler R., Delling G. \& Pfeiffer E.F. 1970. The secretion of calcitonin by theperfused ultimobranchial gland of the hen, p.301-310. In: Taylor S. (Ed.), Calcitonin. Proc. $2^{\text {nd }}$ Int. Symp. London, 1969. William Heinemann Medical Books Ltd, London. 